\title{
$\beta$-Blocker after severe traumatic brain injury is associated with better long-term functional outcome: a matched case control study
}

\author{
R. Ahl ${ }^{1,3}$ - E. P. Thelin ${ }^{4}$ G. Sjölin ${ }^{2}$ - B.-M. Bellander ${ }^{4}$ L. Riddez ${ }^{1}$ P. Talving P $^{5}$ \\ S. Mohseni ${ }^{1,2,3}$ (D)
}

Received: 7 December 2016 / Accepted: 21 February 2017 / Published online: 8 March 2017

(C) The Author(s) 2017. This article is published with open access at Springerlink.com

\begin{abstract}
Purpose Severe traumatic brain injury (TBI) is the predominant cause of death and disability following trauma. Several studies have observed improved survival in TBI patients exposed to $\beta$-blockers, however, the effect on functional outcome is poorly documented.

Methods Adult patients with severe TBI (head AIS $\geq 3$ ) were identified from a prospectively collected TBI database over a 5-year period. Patients with neurosurgical ICU length of stay $<48 \mathrm{~h}$ and those dying within $48 \mathrm{~h}$ of admission were excluded. Patients exposed to $\beta$-blockers $\leq 48 \mathrm{~h}$ after admission and who continued with treatment until discharge constituted $\beta$-blocked cases and were matched to non $\beta$-blocked controls using propensity score matching. The outcome of interest was Glasgow Outcome Scores (GOS), as a measure of functional outcome up to 12 months after injury. GOS $\leq 3$ was considered a poor outcome. Bivariate analysis was deployed to determine differences between groups. Odds ratio and 95\% CI were used to assess the effect of $\beta$-blockers on GOS.
\end{abstract}

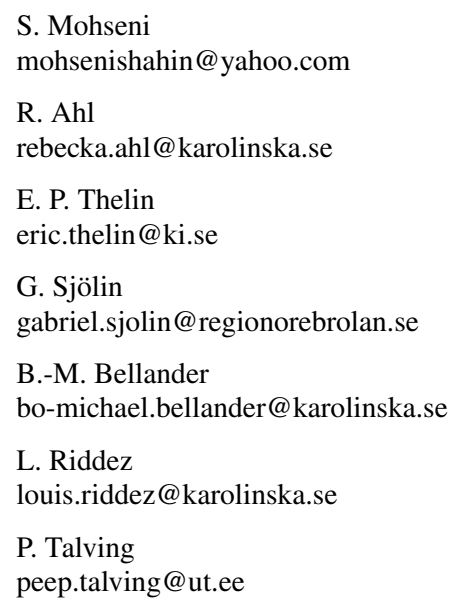

Results 362 patients met the inclusion criteria with $21 \%$ receiving $\beta$-blockers during admission. After propensity matching, 76 matched pairs were available for analysis. There were no statistical differences in any variables included in the analysis. Mean hospital length of stay was shorter in the $\beta$-blocked cases ( 18.0 vs. 26.8 days, $p<0.01)$. The risk of poor long-term functional outcome was more than doubled in non- $\beta$-blocked controls (OR 2.44, 95\% CI 1.01-6.03, $p=0.03)$.

Conclusion Exposure to $\beta$-blockers in patients with severe TBI appears to improve functional outcome. Further prospective randomized trials are warranted.

Keywords Beta-blocker - Traumatic brain injury · Functional outcome
Abbreviations
TBI Traumatic brain injury
GCS Glasgow Coma Scale
ISS Injury Severity Score

1 Division of Trauma and Emergency Surgery, Department of Surgery, Karolinska University Hospital, 17176 Stockholm, Sweden

2 Division of Trauma and Emergency Surgery, Department of Surgery, Orebro University Hospital, 70185 Orebro, Sweden

3 School of Medical Sciences, Orebro University, Orebro, Sweden

4 Department of Clinical Neuroscience, Karolinska Institutet, Solna, 17176 Stockholm, Sweden

5 Department of Surgery, Tartu University Hospital, Puusepa 8, Tartu 50406, Estonia 


$\begin{array}{ll}\text { IRB } & \text { Institutional review board } \\ \text { AIS } & \text { Abbreviated Injury Scale } \\ \text { NICU } & \text { Neurosurgical Intensive Care Unit } \\ \text { LOS } & \text { Length of stay } \\ \text { SBP } & \text { Systolic blood pressure } \\ \text { CT } & \text { Computer tomography } \\ \text { MRI } & \text { Magnetic resonance imaging } \\ \text { NISS } & \text { New Injury Severity Score } \\ \text { GOS } & \text { Glasgow Outcome Score } \\ \text { ICU } & \text { Intensive Care Unit } \\ \text { SD } & \text { Standard deviation } \\ \text { OR } & \text { Odds ratio } \\ \text { CI } & \text { Confidence interval } \\ \text { BB } & \text { Beta-blocker }\end{array}$

\section{Background}

Severe traumatic brain injury (TBI) is the predominant cause of death and disability following trauma. The incidence of TBI is increasing, a trend which is particularly pertinent amongst elderly [1]. Patients who survive TBI often experience long-term neurological impairment. Severe functional disability following TBI is a global public health concern [2].

Multiple risk factors have been associated with an increased morbidity and mortality following TBI including increasing age, diminished Glasgow Coma Scale (GCS) score on admission, episodes of hypotension or hypoxia and increasing Injury Severity Score (ISS) [2-5]. Early interventions after TBI are of paramount importance, nevertheless, despite extensive research, there are few evidence-based interventions for patients with severe brain injury resulting in improved long-term functional outcomes $[6,7]$.

Previous studies have noted associations between nonneurological complications and the catecholamine surge that occur at the time of cerebral insult, which appears proportional to the degree of brain injury [8-10]. It has been postulated that $\beta$-blockers might down-regulate the potential toxic effects of the 'sympathetic storm' following TBI. Sympathetic hyperactivity is thought to increase cerebral vasoconstriction, which is believed to contribute to local edema and increased intracranial pressure. These detrimental events facilitate the progression of secondary brain injury with reduced brain perfusion and oxygenation resulting in increased overall mortality and disability [11]. Consequently, abating the trauma-induced sympathetic storm has the potential to reduce secondary insults and thereby improve immediate and long-term functional outcome. Several clinical studies, along with some prospective experimental investigations, have demonstrated promising effects of $\beta$-blockade on the overall outcome following TBI
[12-17]. These studies have, however, focused mainly on in-hospital mortality rates. We set out to study the effects of $\beta$-blockade in patients experiencing severe TBI with the hypothesis that $\beta$-blocker therapy may improve functional outcome in these instances.

\section{Materials and methods}

The current study has been approved by the ethics committee and has been performed in accordance with the ethical standards laid down in the Declaration of Helsinki. After IRB approval, the traumatic brain injury database of the Neurosurgery Department at Karolinska University Hospital, Stockholm, Sweden, was queried for adult patients (age $\geq 18$ years) sustaining serious to critical TBI (head AIS $\geq 3$ ) admitted between $1 / 2007$ and $12 / 2011$. Given the aim of evaluating the impact of early $\beta$-blockade on longterm functional outcome, patients were stratified to the $\beta$-blocked cases when exposed to $\beta$-blockers within $48 \mathrm{~h}$ of admission and were continued on $\beta$-blockers until discharge from hospital. Patients not receiving $\beta$-blockers constituted the control cohort in this study. Patients suffering penetrating cerebral trauma were excluded. Patients with a neurosurgical intensive care unit (NICU) length of stay (LOS) of less than $48 \mathrm{~h}$ and those with a head AIS of six or those not surviving beyond 2 days following admission were excluded from the study to control for early deaths due to non-survivable injuries.

Patient data were obtained from the TBI registry containing prospectively collected data, including age, gender, admission GCS score, admission systolic blood pressure (SBP), imaging results including computed tomography (CT) or magnetic resonance imaging (MRI), head Abbreviated Injury Scale (AIS), New Injury Severity Score (NISS), Charlson's Comorbidity Index, $\beta$-blocker exposure, the time and type of $\beta$-blocker administered, neurosurgical interventions, NICU LOS, hospital LOS, and mortality. All cases with pertinent ICD-10 codes were reviewed to ensure that the AIS $\geq 3$ was attributed to an intracranial injury (ICD-10 codes S06.1-S06.9). Admission CT scan was defined according to Rotterdam CT classification scores [18]. Glasgow Outcome Score (GOS) at discharge and up to 12 months following trauma was acquired to assess functional outcome (Table 1). At the study site, GOS is regularly assessed at discharge and at 3-6 months post injury at a follow-up appointment at the neurosurgical or rehabilitation clinic. Finally, 12 months after injury, a questionnaire regarding quality of life (TBI-QOL) was sent out to patients. In the current study, GOS at 12 months after injury was utilized to document long-term functional outcome. A GOS of $\leq 3$ was considered to be a poor outcome. 
Table 1 Classification of the Glasgow Outcome Score (GOS)

\begin{tabular}{ll}
\hline Glasgow Outcome Score & Definition \\
\hline GOS 1 & Dead \\
GOS 2 & Vegetative state \\
GOS 3 & Severe disability, dependent state \\
GOS 4 & Moderate disability, independent state \\
GOS 5 & Mild disability, full recovery \\
\hline
\end{tabular}

Table 2 Demographic, clinical information, and outcomes for the total cohort

\begin{tabular}{|c|c|}
\hline Variable & Total cohort $(n=152)$ \\
\hline \multicolumn{2}{|l|}{ Patient characteristics } \\
\hline Male gender & $77.0 \%(117)$ \\
\hline \multicolumn{2}{|l|}{ Age in years } \\
\hline Mean (SD) & $57.5(16.0)$ \\
\hline Median (LQ, UQ) & $62(49,69)$ \\
\hline Age $\geq 55$ years & $70.4 \%(107)$ \\
\hline \multicolumn{2}{|l|}{$\mathrm{CCI}$} \\
\hline Mean (SD) & $3.4(2.6)$ \\
\hline Median (LQ, UQ) & $3(2,5)$ \\
\hline \multicolumn{2}{|l|}{ Specific intracranial injury } \\
\hline Diffuse axonal injury & $5.3 \%(8)$ \\
\hline Focal injury & $11.8 \%(18)$ \\
\hline Epidural hemorrhage & $11.8 \%(18)$ \\
\hline Subdural hemorrhage & $65.1 \%(99)$ \\
\hline Subarachnoid hemorrhage & $5.3 \%(8)$ \\
\hline \multicolumn{2}{|l|}{ Injury severity } \\
\hline Hypotension $(<90 \mathrm{mmHg})$ & $3.3 \%(5)$ \\
\hline $\mathrm{GCS} \leq 8$ & $48.7 \%(74)$ \\
\hline Head AIS $\geq 4$ & $84.9 \%(129)$ \\
\hline Non-head NISS $\leq 9$ & $89.5(136)$ \\
\hline Rotterdam, median (LQ, UQ) & $4(3,5)$ \\
\hline \multicolumn{2}{|l|}{ Neurosurgical interventions } \\
\hline ICP monitoring & $63.8 \%(97)$ \\
\hline Operation & $54.6 \%(83)$ \\
\hline \multicolumn{2}{|l|}{ Outcomes } \\
\hline \multicolumn{2}{|l|}{ NICU LOS } \\
\hline Mean (SD), days & $9.6(8.8)$ \\
\hline Median (LQ, UQ), days & $7(3,15)$ \\
\hline \multicolumn{2}{|l|}{ Hospital LOS } \\
\hline Mean (SD), days & $22.4(18.3)$ \\
\hline Median (LQ, UQ), days & $17(8,30)$ \\
\hline In-hospital mortality & $9.9 \%(15)$ \\
\hline 12-month mortality & $24.3 \%(37)$ \\
\hline GOS $\leq 3$ at discharge & $88.8 \%(135)$ \\
\hline GOS $\leq 3$ at follow-up & $50.7 \%(77)$ \\
\hline
\end{tabular}

GCS Glasgow Coma Scale, CCI Charlson's Comorbidity Index, AIS abbreviated injury scale, NISS New Injury Severity Score, ICP intracranial pressure, NICU neurosurgical intensive care unit, LOS length of stay, GOS Glasgow Outcome Score, $L Q$ lower quartile, $U Q$ upper quartile
The patients included in the study were managed per guidelines set forth by the Brain Trauma Foundation [19].

\section{Statistical analysis}

The primary outcome of interest was GOS at discharge and up to 12 months following discharge. For analysis purposes, several continuous variables were dichotomized using clinically relevant cut-off points (age $\geq 55$ vs. $<55$ years, SBP $\geq 90$ vs. $<90 \mathrm{mmHg}$, GCS $>8$ vs. $\leq 8$, head AIS $=3$ vs. $\geq 4$, and GOS $\leq 3$ vs. $\geq 4$ ). Since the number of confounders was large in comparison with the number of events, cases receiving $\beta$-blocker therapy were matched in a 1:1 ratio to control cases that were not receiving such therapy using propensity score matching. Variables included in the propensity score model were age, gender, NISS, GCS, intracranial injury characteristics, head AIS, Rotterdam CT score, and Charlson's Comorbidity Index. Propensity scores (predicted probability of receiving $\beta$-blockers) were calculated for all patients using binary logistic regression [20]. Each patient receiving $\beta$-blockers was matched to a control not subjected to $\beta$-blockers within a 0.0135 caliper of propensity without replacement. The caliper was equal to one-quarter of a standard deviation (SD) of the logit of the propensity score [21].

Demographic information and clinical characteristics between the matched cohorts were compared using bivariate analysis. The differences between the cohorts were tested for significance using McNemar's test for categorical variables and paired Student's $t$ test or Wilcoxon signed rank test for continuous variables when appropriate. Values are reported as percentages for categorical variables and mean (SD) or median (quartiles) for continuous variables. The difference in risk of suffering an unfavorable GOS $(\leq 3)$ between groups was analyzed and the odds ratio (OR) and 95\% confidence interval (CI) were derived. Values were considered statistically significant at a two-tailed $p$ value of $<0.05$. The statistical analysis was performed using the Statistical Package for Social Science (SPSS Windows $\odot$ ) version 21.0 (SPPS Inc., Chicago, IL).

\section{Results}

During the 5-year study period, a total of 362 patients met the inclusion criteria. Of these, $76(21.0 \%)$ patients received $\beta$-blockers during their hospital admission. After propensity matching, 76 matched pairs $(n=152)$ were available for analysis. The average age of patients was $58 \pm 16$ years and $77.0 \%$ were male. At admission, a total of $48.7 \%$ of patients had a GCS of $\leq 8$ and $84.9 \%$ had a head AIS $\geq 4$ (Table 2). When excluding head AIS scores from the calculation of NISS (non-head NISS) to estimate the burden 
of extracranial injuries in the cohort, $89.5 \%$ of patients had a non-head NISS $\leq 9$ and only $6.6 \%$ of patients had a nonhead NISS exceeding fifteen. Subdural hemorrhage was the most common type of intracranial injury (65.1\%). Intracranial pressure monitoring was used in $63.8 \%$ of the study cohort and $54.6 \%$ underwent evacuation surgery (Table 2).

Table 3 delineates characteristics of the $\beta$-blocked $\left(\mathrm{BB}^{(+)}\right)$cases and their respective controls $\left(\mathrm{BB}^{(-)}\right)$. There were no statistical differences in any variables included in the analysis. No discrepancies were noted with regard to patient characteristics, intracranial injury severity, occurrence of specific types of injury, or required neurosurgical interventions (Table 3). Unfavorable long-term functional outcomes $(\mathrm{GOS} \leq 3)$ were detected in $50.7 \%$ of the total cohort (Table 2). Following propensity score matching, the mean NICU LOS in the $\mathrm{BB}^{(+)}$group and in the $\mathrm{BB}^{(-)}$control group was $8.5 \pm 11.7$ vs. $10.8 \pm 9.1$ days $(p=0.09)$. The mean hospital LOS was shorter in the $\mathrm{BB}^{(+)}$cohort $(18.0$ days vs. 26.8 days, $p<0.01$ ) (Table 4 ). There was no difference in unfavorable GOS at discharge between the two cohorts $\left(88.2 \%\right.$ for $\mathrm{BB}^{(+)}$vs. $89.5 \%$ for $\left.\mathrm{BB}^{(-)}, p=1.00\right)$. At follow-up, however, the $\mathrm{BB}^{(+)}$group experienced significantly fewer cases of poor long-term functional outcome $(\mathrm{GOS} \leq 3)$ than their $\mathrm{BB}^{(-)}$counterparts, with 42.1 vs. $59.2 \%$, respectively $(p=0.03)$ (Table 4$)$. The risk of poor long-term functional outcome was more than doubled in non- $\beta$-blocked patients (OR 2.44, 95\% CI 1.01-6.03, $p=0.03$ ). Table 5 depicts the breakdown of GOS scores between $\mathrm{BB}^{(+)}$and $\mathrm{BB}^{(-)}$patients at discharge and at follow-up.

\section{Discussion}

The current study observed that severe TBI cases subjected to early and continuous $\beta$-blocker therapy had a significantly better long-term functional outcome compared to controls without BB exposure. To the authors' best knowledge, there are no previous investigations evaluating
Table 3 Demographics and clinical information prior to and following propensity score matching

\begin{tabular}{|c|c|c|c|c|c|c|}
\hline & \multicolumn{3}{|c|}{ Before matching } & \multicolumn{3}{|l|}{ After matching } \\
\hline & $\begin{array}{l}\mathrm{BB}^{(-)} \\
(n=286)\end{array}$ & $\begin{array}{l}\mathrm{BB}^{(+)} \\
(n=76)\end{array}$ & $p$ & $\begin{array}{l}\mathrm{BB}^{(-)} \\
(n=76)\end{array}$ & $\begin{array}{l}\mathrm{BB}^{(+)} \\
(n=76)\end{array}$ & $p$ \\
\hline \multicolumn{7}{|l|}{ Patient characteristics } \\
\hline Male gender & $75.2 \%(215)$ & $75.0 \%(57)$ & 1.0 & $78.9 \%(60)$ & $75 \%(57)$ & 0.61 \\
\hline Age in years & & & $<0.001$ & & & 0.68 \\
\hline Mean (SD) & $46.0(18.6)$ & $57.2(16.3)$ & & $57.9(15.8)$ & $57.2(14)$ & \\
\hline Median (LQ, UQ) & $47(29,62)$ & $62(50,69)$ & & $62(49,69)$ & $62(50,69)$ & \\
\hline Age $\geq 55$ years & $39.5 \%(113)$ & $71.1 \%(54)$ & $<0.001$ & $69.7 \%(53)$ & $71.1 \%(54)$ & 1.00 \\
\hline CCI & & & $<0.001$ & & & 0.70 \\
\hline Mean (SD) & $1.9(2.2)$ & $3.5(2.4)$ & & $3.4(2.7)$ & $3.5(2.1)$ & \\
\hline Median (LQ, UQ) & $1(0,3)$ & $3(2,5)$ & & $3(1,5)$ & $3.0(2,5)$ & \\
\hline \multicolumn{7}{|l|}{ Specific intracranial injury } \\
\hline Diffuse axonal injury & $11.5 \%(33)$ & $5.3 \%(4)$ & 0.12 & $5.3 \%(4)$ & $5.3 \%(4)$ & 1.00 \\
\hline Focal injury & $16.4 \%(47)$ & $13.2 \%(10)$ & 0.60 & $10.5 \%(8)$ & $13.2 \%(10)$ & 0.73 \\
\hline Epidural hemorrhage & $18.2 \%(52)$ & $11.8 \%(9)$ & 0.23 & $11.8 \%(9)$ & $11.8 \%(9)$ & 1.00 \\
\hline Subdural hemorrhage & $37.1 \%(106)$ & $63.2 \%(48)$ & $<0.001$ & $67.1 \%(51)$ & $63.2 \%(48)$ & 0.58 \\
\hline Subarachnoid hemorrhage & $9.1 \%(26)$ & $5.3 \%(4)$ & 0.34 & $5.3 \%(4)$ & $5.3 \%(4)$ & 1.00 \\
\hline \multicolumn{7}{|l|}{ Injury severity } \\
\hline Hypotension (<90 mmHg) & $4.5 \%(13)$ & $3.9 \%(3)$ & 1.0 & $2.6 \%(2)$ & $3.9 \%(3)$ & 1.00 \\
\hline $\mathrm{GCS} \leq 8$ & $62.9 \%(180)$ & $44.7 \%(34)$ & 0.01 & $52.6 \%(40)$ & $44.7 \%(34)$ & 0.18 \\
\hline Head AIS $\geq 4$ & $86.0 \%(246)$ & $84.2 \%(64)$ & 0.71 & $85.5 \%(65)$ & $84.2 \%(64)$ & 1.00 \\
\hline Non-head NISS $\leq 9$ & $71.7 \%(205)$ & $92.1 \%(70)$ & 0.001 & $86.8 \%(66)$ & $92.1 \%(70)$ & 0.30 \\
\hline $\begin{array}{l}\text { Rotterdam, median (LQ, } \\
\text { UQ) }\end{array}$ & $3(3,4)$ & $4(3,4)$ & & $4(3,4)$ & $4(3,4)$ & \\
\hline \multicolumn{7}{|l|}{ Neurosurgical interventions } \\
\hline ICP monitoring & $69.2 \%(198)$ & $64.5 \%(49)$ & 0.49 & $63.2 \%(48)$ & $64.5 \%(49)$ & 1.00 \\
\hline Operation & $44.1 \%(126)$ & $60.5 \%(46)$ & 0.01 & $48.7 \%(37)$ & $60.5 \%(46)$ & 0.18 \\
\hline
\end{tabular}

$B B \beta$-blockade, GCS Glasgow Coma Scale, CCI Charlson's Comorbidity Index, AIS Abbreviated Injury Scale, NISS New Injury Severity Score, ICP Intracranial Pressure, $L Q$ lower quartile, $U Q$ upper quartile 
Table 4 Outcomes prior to and following propensity score matching

\begin{tabular}{|c|c|c|c|c|c|c|}
\hline \multirow[t]{2}{*}{ Outcomes } & \multicolumn{3}{|l|}{ Before matching } & \multicolumn{3}{|l|}{ After matching } \\
\hline & $\begin{array}{l}\mathrm{BB}^{(-)} \\
(n=286)\end{array}$ & $\begin{array}{l}\mathrm{BB}^{(+)} \\
(n=76)\end{array}$ & $p$ & $\begin{array}{l}\mathrm{BB}^{(-)} \\
(n=76)\end{array}$ & $\begin{array}{l}\mathrm{BB}^{(+)} \\
(n=76)\end{array}$ & $p$ \\
\hline NICU LOS & & & 0.03 & & & 0.09 \\
\hline Mean (SD) days & $11.1(9.5)$ & $8.5(8.3)$ & & $10.8(9.1)$ & $8.5(11.7)$ & \\
\hline $\begin{array}{l}\text { Median (LQ, UQ) } \\
\text { days }\end{array}$ & $8.4(3.0,17.0)$ & $5.0(3.0,12.0)$ & & $8.0(3.0,16.0)$ & $5.0(3.0,12.0)$ & \\
\hline \multicolumn{7}{|l|}{ Hospital LOS } \\
\hline Mean (SD), days & $24.2(18.7)$ & $18.0(12.6)$ & $<0.01$ & $26.8(21.7)$ & $18.0(24.9)$ & $<0.01$ \\
\hline $\begin{array}{l}\text { Median (LQ, UQ), } \\
\text { days }\end{array}$ & $19(10,32)$ & $15(8,24)$ & & $21(9,34)$ & $15(8,24)$ & \\
\hline In-hospital mortality & $6.3 \%(18)$ & $11.8 \%(9)$ & 0.14 & $7.9 \%(6)$ & $11.8 \%(9)$ & 0.58 \\
\hline 12-month Mortality & $14.0 \%(40)$ & $22.4 \%(17)$ & 0.08 & $26.3 \%(20)$ & $22.4 \%(17)$ & 0.70 \\
\hline GOS $\leq 3$ at discharge & $88.5 \%(253)$ & $88.2 \%(67)$ & 1.00 & $89.5 \%(68)$ & $88.2 \%(67)$ & 1.00 \\
\hline GOS $\leq 3$ at follow-up & $42.7 \%(122)$ & $42.1 \%(32)$ & 1.00 & $59.2 \%(45)$ & $42.1 \%(32)$ & 0.03 \\
\hline
\end{tabular}

$B B$-blockade, GCS Glasgow Coma Scale, CCI Charlson's Comorbidity Index, AIS Abbreviated Injury Scale, NISS New Injury Severity Score, ICP Intracranial Pressure, $L Q$ lower quartile, $U Q$ upper quartile

\begin{tabular}{|c|c|c|c|c|c|c|}
\hline \multirow[t]{3}{*}{ Functional outcome } & \multicolumn{3}{|c|}{ GOS at discharge } & \multicolumn{3}{|c|}{ GOS at follow-up } \\
\hline & $\mathrm{BB}^{(-)}$ & $\mathrm{BB}^{(+)}$ & $p$ & $\mathrm{BB}^{(-)}$ & $\mathrm{BB}^{(+)}$ & $p$ \\
\hline & $n(\%)$ & $n(\%)$ & & $n(\%)$ & $n(\%)$ & \\
\hline GOS $\leq 3$ & $68(89.5)$ & $67(88.2)$ & 1.00 & $45(59.2)$ & $32(42.1)$ & 0.03 \\
\hline GOS 1 & $6(7.9)$ & $9(11.8)$ & & $14(18.4)$ & $13(17.1)$ & \\
\hline GOS 2 & $4(5.3)$ & $0(0)$ & & $1(1.3)$ & $0(0)$ & \\
\hline GOS 3 & $58(76.3)$ & $58(76.3)$ & & $30(39.5)$ & $19(25.0)$ & \\
\hline GOS 4 & $8(10.5)$ & $9(11.8)$ & & $17(22.4)$ & $28(36.8)$ & \\
\hline GOS 5 & 0 & 0 & & $14(18.4)$ & $16(21.1)$ & \\
\hline
\end{tabular}

GOS Glasgow Outcome Score
Table 5 Functional outcomes at discharge and follow-up in the matched cohorts far focused on in-hospital survival but not on long-term functional outcome.

We noted that a total of $24.3 \%$ of patients died within the 12 -month study period and $9.9 \%$ of the deaths occurred during the in-hospital phase of care after excluding patients with non-survivable injuries (death within $48 \mathrm{~h}$ of admission). Our findings also indicate that the cohort of initial survivors experienced a poor early functional outcome with $88.8 \%(n=135 / 152)$ assigned a GOS of $\leq 3$ at discharge and $50.7 \%(\mathrm{n}=77 / 152)$ at follow-up. Likewise, there was no significant difference between the $\mathrm{BB}^{(+)}$and $\mathrm{BB}^{(-)}$groups on analysis of GOS at discharge. However, the $\beta$-blocker exposed cohort did have a significantly shortened mean hospital LOS ( $18.0 \pm 24.9$ vs. $26.8 \pm 21.7$ days, $p<0.01)$.

Interestingly, a significant long-term benefit on functional outcome was noted with a two-fold reduction of poor outcome measured by GOS (OR 2.44, 95\% CI 1.01-6.03, $p=0.03$ ) up to 1 year after injury. Consequently, early tional recovery [24]. Nevertheless, clinical studies have so 
initiation of $\beta$-blocker therapy and continuous exposure throughout the hospital stay appears to have a therapeutic role in long-term neurological recovery. We speculate that an extended recovery span is required beyond the hospital LOS for improved outcomes after severe TBI, typically through multi-interventional neuro-rehabilitation efforts.

Previous studies have demonstrated that pre-admission and in-hospital $\beta$-blocker exposure is associated with improved in-hospital survival following TBI [14, 25]. While there is an obvious overlapping relationship between mortality and neurologic recovery, there was no difference between $\mathrm{BB}^{(+)}$and $\mathrm{BB}^{(-)}$groups in terms of in-hospital mortality (11.8 vs. $7.9 \%, p=0.58)$ or overall mortality (up to 12 months) (26.3 vs. $22.4 \%, p=0.70$ ). We speculate that this is a consequence of selection bias introduced by the exclusion of unavoidable deaths due to non-survivable injury (deaths $\leq 48 \mathrm{~h}$ of admission), the smaller sample size, and the reduction in confounders through propensity score matching. Patients were matched according to variables, such as age, injury severity (AIS, NISS, Rotterdam CT score and GCS) and comorbidity (Charlson's Comorbidity Index), which are individually known to affect survival perspectives following traumatic injury. As a result, the potential for mortality differences between the subgroups is reduced.

To the best of our knowledge, this is a pioneering investigation observing long-term benefits of $\beta$-blocker administration following severe TBI. Nevertheless, there are several limitations to the study. First, while the median time for long-term GOS assessment was close to 12 months, some patients had the assessment later as well as earlier. Through our experience, these discrepancies result in very small variations in the data and thus represent only a minor limitation. Second, while GOS is the gold standard for functional assessment, it might be too crude to assess complaints related to post-traumatic stress disorder or qualityof-life assessment, which we believe should be the subject of future studies [26, 27]. Third, secondary cerebral injuries or other complications during the admission period or after discharge, which invariably have an impact on longterm functional outcome, could not separately be accounted for in the current study. Finally, the precise cause of death could not be determined.

\section{Conclusion}

Early and continuous exposure to $\beta$-blocker medication in patients with severe TBI appears to improve functional outcomes. Further prospective randomized trials and investigation into the underlying mechanisms of this effect are warranted.

\section{Compliance with ethical standards}

This study has been approved by the ethics committee and has been performed in accordance with the ethical standards laid down in the Declaration of Helsinki. Due to the retrospective nature of the study, no informed consent was obtained from the included cohort as judged by the ethics committee.

Conflict of interest Dr. Ahl, Dr. Thelin, Dr. Sjolin, Dr. Bellander, Dr. Riddez, Dr. Talving, and Dr. Mohseni have no conflicts of interest to report and have received no financial support in relation to this manuscript.

Open Access This article is distributed under the terms of the Creative Commons Attribution 4.0 International License (http:// creativecommons.org/licenses/by/4.0/), which permits unrestricted use, distribution, and reproduction in any medium, provided you give appropriate credit to the original author(s) and the source, provide a link to the Creative Commons license, and indicate if changes were made.

\section{References}

1. Roozenbeek B, Maas AI, Menon DK. Changing patterns in the epidemiology of traumatic brain injury. Nat Rev Neurol. 2013;9(4):231-236.

2. Corrigan JD, Selassie AW, Orman JA. The epidemiology of traumatic brain injury. J Head Trauma Rehabil. 2010;25(2):72-80.

3. Mosenthal AC, Livingston DH, Lavery RF, Knudson MM, et al. The effect of age on functional outcome in mild traumatic brain injury: 6-month report of a prospective multicenter trial. J Trauma Acute Care Surg. 2004;56(5):1042-8.

4. Munro PT, Smith RD, Parke TR. Effect of patients' age on management of acute intracranial haematoma: prospective national study. BMJ. 2002;325(7371):1001.

5. Davis DP, Serrano JA, Vilke GM, Sise MJ, et al. The predictive value of field versus arrival Glasgow Coma Scale score and TRISS calculations in moderate-to-severe traumatic brain injury. J Trauma Acute Care Surg. 2006;60(5):985-90.

6. Maas AI, Steyerberg EW, Butcher I, Dammers R, et al. Prognostic value of computerized tomography scan characteristics in traumatic brain injury: results from the IMPACT study. J Neurotrauma. 2007;24(2):303-14.

7. Maas AI, Marmarou A, Murray GD, Teasdale SG, et al. Prognosis and clinical trial design in traumatic brain injury: the IMPACT study. J Neurotrauma. 2007;24(2):232-8.

8. Heffernan DS, Inaba K, Arbabi S, Cotton BA. Sympathetic hyperactivity after traumatic brain injury and the role of betablocker therapy. J Trauma Acute Care Surg. 2010;69(6):1602-9.

9. Kemp CD, Johnson JC, Riordan WP, Cotton BA. How we die: the impact of nonneurologic organ dysfunction after severe traumatic brain injury. Am Surg. 2008;74(9):866-72.

10. Zygun DA, Kortbeek JB, Fick GH, Laupland KB, et al. Non-neurologic organ dysfunction in severe traumatic brain injury. Crit Care Med. 2005;33(3):654-60.

11. Ley E, Scehnet J, Park R, Schroff S, et al. The in vivo effect of propranolol on cerebral perfusion and hypoxia after traumatic brain injury. J Trauma Acute Care Surg. 2009;66:154-61.

12. Schroeppel TJ, Fischer PE, Zarzaur BL, Magnotti LJ, et al. Betaadrenergic blockade and traumatic brain injury: protective? J Trauma Acute Care Surg. 2010;69(4):776-82.

13. Arbabi S, Campion EM, Hemmila MR, Barker M, et al. Betablocker use is associated with improved outcomes in adult trauma patients. J Trauma Acute Care Surg. 2007;62(1):56-61. 
14. Cotton BA, Snodgrass KB, Fleming SB, Carpenter RO, et al. Beta-blocker exposure is associated with improved survival after severe traumatic brain injury. J Trauma Acute Care Surg. 2007;62(1):26-33.

15. Inaba K, Teixeira PG, David JS, Chan LS, et al. Beta-blockers in isolated blunt head injury. J Am Coll Surg. 2008;206(3):432-8.

16. Ko A, Harada MY, Barmparas G, Thomsen GM, et al. Early propranolol after traumatic brain injury is associated with lower mortality. J Trauma Acute Care Surg. 2016;80(4):637-42.

17. Mohseni S, Talving P, Thelin E, Wallin G, et al. The effect of beta-blockade on survival in a Swedish cohort of isolated severe traumatic brain injury. World J Surg. 2015;39(8):2076-83.

18. Maas AI, Hukkelhoven CW, Marshall LF, Steyerberg EW. Prediction of outcome in traumatic brain injury with computed tomographic characteristics: a comparison between the computed tomographic classification and combinations of computed tomographic predictors. Neurosurgery. 2005;57(6):1173-82.

19. Bratton SL, Chestnut RM, Ghajar J, McConnell Hammond FF, et al. Guidelines for the management of severe traumatic brain injury. VIII. Intracranial pressure thresholds. J Neurotrauma. 2008;25(3):276-8.

20. Rubin DB, Thomas N. Matching using estimated propensity scores: relating theory to practice. Biometrics. 1996;52(1):249-64.
21. D'Agostino RB Jr. Propensity score methods for bias reduction in the comparison of a treatment to a non-randomized control group. Statist Med. 1998;17:2265-81.

22. Clifton GL, Ziegler MG, Grossman RG. Circulating catecholamines and sympathetic activity after head injury. Neurosurgery. 1981;8:10-4.

23. Hortnagl H, Hammerle AF, Hackl JM, Brücke T, et al. The activity of the sympathetic nervous system following severe head injury. Intensive Care Med. 1980;6(3):169-77.

24. Woolf PD, Hamill RW, Lee LA, Cox C, et al. The predicative value of catecholamines in assessing outcome in traumatic brain injury. J Neurosurg. 1987;66:875-82.

25. Mohseni S, Talving P, Wallin G, Ljungqvist $\mathrm{O}$, et al. Preinjury beta-blockade is protective in isolated severe traumatic brain injury. J Trauma Acute Care Surg. 2014;76:804-8.

26. Jennett B, Snoek J, Bond MR, Brooks N. Disability after severe head injury: observations on the use of the Glasgow Outcome Scale. J Neurol Neurosurg Psychiatry. 1981;44:285-93.

27. Ahl R, Sjolin G, Mohseni S. Does early beta-blockade in isolated severe traumatic brain injury reduce the risk of post traumatic depression? Injury. 2017;48(1):101-105. 